\title{
3. The Kalpurtu Water Cycle: Bringing Life to the Desert of the South West Kimberley
}

\author{
Patrick Sullivan, Hanson Boxer (Pampila), Warford Bujiman \\ (Pajiman) and Doug Moor (Kordidi)
}

Water is neither a commodity nor simply an element for the Walmajari people of the Great Sandy Desert fringe. It links the people and their livelihoods directly to the creatures of myth and ritual, the Kalpurtu, who have enlivened the natural landscape since the beginning of time. This chapter lays out some of the information on the cultural importance of water which Sullivan recorded during fieldwork organised by Boxer, Bujiman and Moor during the hot dry season of October 2000. The field visits took place over a period of about one week in the vicinity of Yakanarra community, which is about 65 kilometres south-west of Fitzroy Crossing (Toussaint et al., 2001). What follows is a description of the current beliefs and activities of the Walmajari people of this part of the Fitzroy region. It begins with the beliefs and practices of a fairly recent past. In a later section the modern situation is described. Although the people of Yakanarra community do not nowadays hunt, fish and gather bush foods and medicines in quite the same way of their parents and grandparents, several of the older people spent their younger years living in a traditional manner on the periphery of white owned cattle enterprises. Bush food is still an important part of the community's diet and a significant element of cultural identity. Fresh water sources are still important for their food resources and recreation. They may be vital from time to time, since an individual's survival can still depend on finding water when vehicles break down, bog in sand, or when people scout around on foot from the base of a bush camp. Just as the importance of water in this arid area has not diminished, the belief system and practices that surround it remain strong also. Elsewhere in the Kimberley similar beliefs and practices have formed the basis of claims of existing native title (Vachon, 2006). No native title claim has been made in the Yakanarra region, and it is unlikely that recognition of their title could do justice to the richness of the belief system that underlies it, nor do much to protect the spiritual attachment that members of the community have to their local water sources. On the contrary, this chapter shows the wide gap between a system of property based on registered title rights, and a holistic cultural system based in nurturing the natural environment through a combination of appropriate spiritual practices and the use of practical local knowledge. 
The Walmajari people of Yakanarra community live on the flood plain of the Fitzroy River and its tributaries. In the wet season, streams flood down off the Saint George Ranges filling the creek systems that feed into the Fitzroy. Swollen with waters from its catchment in the central Kimberley, at the height of the wet season the Fitzroy escapes its banks and floods back onto the plains mingling with the water coming down from the Saint George Ranges. Much of the land goes under water. Movement is restricted and settlement limited to well drained areas of high ground. As the wet season abates the creeks dry out to a series of billabongs, claypans (pindi) gradually shrink, the billabongs themselves eventually give out and both people and animals rely on the few permanent rockpools in the ranges, and the soaks (jila) in the sandhills of the plains. To the Walmajari people the rain is 'god-given' in more than a simple poetic sense. It is the result of the interaction of the people and the first mythic beings of the Dreamtime - the kalpurtu. All of these water sources are linked in Aboriginal culture by the actions of the kalpurtu. Kalpurtu inhabit the jila-permanent spring waters called 'living water' in Aboriginal English or Wunggur Ngaba. The description of cultural attachment to water in this chapter shows how the kalpurtu are the centre and source of all water and the animal species associated with it.

\section{Kalpurtu jila, living water}

The very first beings were the kalpurtu. They are both man and serpent. In this region they were sent out from their centre of origin at Paliyira a Walmajari jila west of Yakanarra. One kalpurtu in particular defines the region of Yakanarra community and its peoples. This is Moankanambi. In his early journeys he arrived at Pelican Billabong (the original Yakanarra, close to the Old Cherrabun station homestead). Here he looked for a deep water jila to settle in. He drew a boomerang out of his stomach, in the manner that mabarn or 'witchdoctors' can, and threw it three times in three different directions in search of water. Each time it returned to him since the water it found was not deep enough. In the process it made the flood plains that are cut by Gap Creek (Kungurrmin), Cherrabun Creek (Mankurin) and Christmas Creek. On the fourth throw it sank into the jila called Moankanambi near Mona Bore on Go Go station, and the kalpurtu knew that this would be his resting place. He journeyed there and that is where he remains. When the hot season builds up and clouds appear in the sky over the desert it is Walmajari practice to dig out the jila in a ritual manner to release the water and to make rain.

The jila that hold kalpurtu are normally dangerous to approach. The kalpurtu take the form of snakes with long beards. They are not like any other Dreamtime snake that may also be a known species, for instance a King Brown or a Carpet 
Snake. The kalpurtu is a unique snake. If the kalpurtu is disturbed it can bring misfortune or death. It is important to approach the kalpurtu singing the correct song for the particular kalpurtu and his jila. Walmajari will emphasise that it cannot be just any song, nor can it be a made up song or 'dreamed' song that may be appropriate in other contexts. It is the song given to the people from the Dreamtime, and it makes the kalpurtu happy to hear it because he knows he has not been forgotten.

\section{Rainmaking in the hot season}

The kalpurtu lies deep underground in the waters of the jila. In a sense, the kalpurtu is the water of the jila, just as he is the rain that the people invoke him to produce. In the hot season, lying in his jila, he spits out vapour to make the clouds. There are several kinds of clouds. Mayilbu is low and near the ground and signals the need to start the rainmaking ritual. Nangkali clouds hold kalpurtu. The Kudukudu clouds contain the seeds of food species that will wash into the ground with the rain and grow and multiply. When the clouds lie close to the earth it is the right time to make rain. The men gather rain stones (punu) that are to be found in the vicinity of the jila. These stones are distinguished from the others on the ground by the scrutiny of the expert old men. They are taken to the jila, where a ritual is performed that is secret. Then the men dig while singing to the kalpurtu and the women sing in a group to one side. When the lightning starts to crack in the sky they switch to the lightning song. This way the lightning knows that they are singing to make rain and will avoid striking them, so they are not afraid. Possibly at the same time that the men sing and dig and cover themselves with the clay of the jila, or possibly a few days later, the rain comes. The women beat the air and the ground with bushes and cry out to the kalpurtu to give them plenty of food in the coming season.

The kalpurtu at Moankanambi has other jila and a chain of claypans (pindi) as part of his complex of water sources. The jila called Lumarta, which is some distance away, belongs to him and is linked in local Walmajari conception to the main site. The pindi have their own song which is performed while digging out the jila and also when visiting the pindi. The song asks the kalpurtu to fill the pindi with good food such as frogs and goanna.

\section{Kalpurtu rain brings food}

Walmajari people will explain that the rain contains invisible seeds that go into the ground. These produce, in a few days or weeks, the animal species associated with water - goanna, frogs, land crabs (kalbagor), fresh water eels, 
turtle, fish, ducks, as well as non-food birds such as pidrureri (not identified) and the panjur which is a seagull that arrives in the desert at this season. With the crabs, eels and turtles this bird gives a strange and dissonant echo of the sea in a land usually seen as the opposite. This echo can be seen also in the presence of the remains of large sea shells, conch and baler, found on the ground surrounding jila. These are said to have been left by kalpurtu, but can also be seen to be the result of trade routes from the coast into the desert. This, too, probably accounts for the common finding of ground stone axe heads of black granite in the vicinity of jila. These do not originate in the region.

The deep, cool underground water which is animated by kalpurtu thus gives birth to the cycle of water, beginning with the clouds, then the rain that bears the seeds of food species, and necessarily the running creeks, the billabongs, claypans and rockpools. These various water sources all have their particular qualities and uses, much of them dependent on season.

\section{Ways of catching fish and water borne food species}

At the very height of the wet season mobility is affected and water sources cannot be easily used. Yakanarra people are confined to areas of high ground as tracks are unusable. This was one of their reasons for moving from the first outstation at Old Cherrabun station. The creek rises in the wet and floods the plain making the old settlement an island on which the community would be marooned for some time. As the water subsides, the creeks and waterholes become accessible once more. Nowadays the people go fishing with nets and lines. The common practice is to get bait with throw nets and then to set hand lines. When approaching a fishing spot men and women will call out to kalpurtu and sing his song asking for a plentiful catch, since ultimately it is the kalpurtu who has put the food in the water sources. Fish is an important part of the diet, particularly so during mourning periods when meat is forbidden.

In the past fishing was often a group exercise. In the full flood of the wet season, trees and broken branches are swept along the rivers binding together then snagging in the creek bed and serving as a trap for water-borne sand. As the floods abate, islands and sand banks appear, creating channels at first which gradually dry out to discrete pools and billabongs. Using these channels, sand banks and the banks of the river, groups of men and women would work together pushing bundles of tied branches, leaves and grasses through the water, herding and trapping whatever could be found. According to older community members who participated in these drives, an abundant variety of food would 
be heaped onto the banks in this way, including small crocodile, barramundi (pulka), bream (tjampinpurra), catfish (kulumatjardi), and freshwater sawfish (Pristis microdon).

Another method more suitable to discrete pools is to poison the fish with the bark of the majarla tree (Barringtonia acutangula, freshwater mangrove). This tree grows conveniently along the banks of rivers and is very commonly found. In the days of stone axes the trees would be cut down and carried on the shoulders of several men to an appropriate pool. Nowadays it is possible to cut the tree into suitable logs in situ with a steel axe and transport these to the pool. These poison logs are called limara. Normally, cutting the logs occurs the day before their use, they are left overnight and used the next morning. The correct name for the limara was given by kalpurtu and in their cut state they are associated with the Warlungarri Dreaming. This starts in the north on Oobagooma station then travels to Yeeda and along the Fitzroy to Noonkanbah, then to the east where it terminates in Sturt Creek. The kalpurtu who gave the people the technique of using limara was a mabarn or 'witchdoctor' who also taught the Warlungarri dance. This is a public dance of men, women and children that is widespread in the Kimberley. It precedes initiation ceremonies and is sometimes performed at public festivals simply for amusement.

The fish poisoning technique is most effective when there is a good sized group of people who sit around the edges of the pool, half submerged, and pound the bark of the logs in the pool, eventually stripping it from the log and throwing it into the water until the pool is evenly covered. The bark produces a soapy substance, the frothy water that results is called jangarla. The degree of saturation of the pool and the even coverage of the poison is judged by the red stain that spreads from the bark. When this is sufficient the fishers retire to wait. After an hour or two the fish rise to the surface, first jumping to escape the pool, then expiring and floating on the surface where they are easily gathered.

Barramundi and bream can be caught in this way, but during this visit only the bony lagarr fish surfaced. While the flesh is good, the hundreds of tiny hairlike bones make eating them a trying experience. The technique that Walmajari people developed to deal with this problem and make use of even this food source is to cook the fish in the normal way over coals, then to let it dry in the sun for one or two days. It can then be pounded into powder with a rock, mixed into a paste with water and eaten.

\section{Seasonal use of water sources}

Some pools in the major rivers such as the Fitzroy remain throughout the wet season. These can have mythological significance. One such is Parrakapan on 
the Fitzroy River near Old Cherrabun homestead. This was a favoured site for spearing crocodile in the station days. This pool has a kalpurtu as does another related waterhole on the Forrest River in the region of Jubilee Downs. These kalpurtu were put in the river pools by the Dreamtime figure Wurnyambul. He was himself a kalpurtu but was also a bird, a black bird which makes a sound like a man. He came from over the Leopold Ranges. He killed two snakes with a stick and when he called their names they made the two rivers. They persist in the permanent water of their respective waterholes. These are said to be 'living waters' like a jila but in the creek. Other waterholes that dry out are called jumu. This story, like the lore associated with limara logs shows how kalpurtu belief shades into more common Dreamtime or ngarangani stories and overlaps with the northern belief complex centred on wungurr, again a mythological snake standing for the creative force itself, but with different characteristics to those of kalpurtu.

\section{Billabongs - jumu}

There are few such large permanent waterholes. Most billabongs will dry out. Kurrkarra billabong in Gap Creek (Kungurrmin) is a good example of this. This billabong was a favoured meeting place between the bush people and the station hands. Here they would become acquainted with flour, tea and sugar, station rations shared by their more acculturated kinsmen. This rapidly replaced nargati, the flour made from grass seed. Several older Walmajari, among them Pajiman, one of the authors of this chapter, grew up here before their parents decided to venture life at Old Cherrabun station. Driftwood in the dried up billabong attests to the power of the water in flood. It becomes a useful source of fuel. When the billabong dried up the people would retreat to the rockholes in the ranges - Bulany, Maraltjidi, Tjinan, Karninantjadi, or else they would spread out onto the plains and rely on the water of jila.

\section{Claypans - pindi}

By this time the water in the chain of pindi, the claypans that have been filled with kalpurtu rain, has also dried out. The pindi are said to belong to the kalpurtu of Moankanambi as part of his complex of jila. When the main jila is dug out special songs for the pindi are sung. These have been given by kalpurtu from the Dreamtime. He is called upon to make the pindi deep and rich with food. The songs are again sung when the pindi are visited. This is done to make the kalpurtu happy, even in the dry season when no water or apparent life remains. Leaving the pindi, the people would rely on the rockholes and jila. 


\section{Rockholes, springs and soaks - jila}

Bulany is a spring-fed rockhole in the range above Kurrkarra billabong. It is nowadays an important recreation site for the community. Children learn to swim here and the school teachers like to camp. It is popular for fishing. Fresh water eels can be found here. Within walking distance are other rock pools but these are not permanent. However, the presence of water in the ground encourages lush vegetation which produces a micro-climate among the rocks and is a source of food and shade to animals and birds. These springs, like the jila in the sand hills of the plains, are favoured hunting locations in the dry season. Attention turns from fish and water based food species to hunting kangaroo and emu. The technique is to hide in bushes at the edge of known watering places, in the old days with a spear, now with a rifle, and wait for the animal to appear. Several jila visited during this survey showed tracks or scats of kangaroo and emu. The jila become centrally important in the dry season. As Pampila puts it, 'jila is like a city for our people. It is where everyone goes back to'. This is a fine image because, not only does it suggest Walmajari go 'home' to their jila just as white people customarily go home to the cities, it also suggest the comfort, familiarity and the life-supporting aspects of jila to the local people.

The word 'jila' is also given to soaks that are found and dug out in dry creek beds. One such is at the junction of Gap Creek (Kungurrmin) and Cherrabun Creek (Mankurin). Knowledge of the location of these was essential for survival in the past and remains important local knowledge, since exposure to the heat without water for whatever reason poses serious risk. This knowledge has usually been passed down through the generations, but knowledge of the location of soak waters can also be divined in dreams, or more practically by listening to bird song and seeking out where certain birds congregate. Because the jila, rockholes and fishing places are used cyclically by the local people as seasons change, they are also sites of shared memory and history. Visiting these places is not just a practical matter of finding water, but also an occasion for remembering birth places, significant life activities and the death of previous generations.

\section{Communities, land, food species and water}

In the past, in the long hot period before the first rains, the people would spread out across the landscape in small groups capable of exploiting the existing water resources without completely depleting them. When the season was right they would begin the cycle once more with rainmaking ceremonies celebrating the kalpurtu. Nowadays, the bores that have been put down in traditional water 
sources offer more plentiful and reliable supplies, and make possible the developed communities with their schools and stores that dot the landscape of the Fitzroy River system, even on the desert fringe, such as Yakanarra and Djugerari. These communities have each developed from their own unique history and each has its own cultural circumstances. Yet they are part of the same broad process of development of the Kimberley and share both cultural and practical concerns that arise from this.

Go Go, Cherrabun and Christmas Creek pastoral stations were settled by the Emmanuel brothers in the last decades of the 19th century. The white people and their stock began to compete with Walmajari people for access to water. There was often conflict over spearing of stock that came to waterholes to drink. There was also a belief among the pastoralists that the presence of Aboriginal people at water sources deterred the cattle, which lost condition. The early period of violent conflict gave way to a period of accommodation in which local Aboriginal people worked on the stations during the dry season and went back to the bush for the wet. These station workers encouraged their kin, who remained at large in the desert to the south, to come and settle at the stations. Several older people in the Fitzroy Crossing region remember walking into the stations with their parents after leading a traditional life in the bush. The people who grew up on the stations retained the use of their languages and their knowledge of the land with its sacred and everyday stories.

During the assimilation period in Western Australia many Aboriginal people left the stations for a variety of reasons. The pastoralists began to rely more heavily on paddocking and machinery for stock work and employed smaller work forces. This happened at the same time as they were required to pay their workers cash wages. As the older pastoralists left the industry the new owners of stations tended to run their properties like the farms in the more settled areas, where they exercised exclusive possession. The Emmanuels compromised by allowing the excision of two areas on Go Go and Christmas Creek stations on which the Department of Aboriginal Affairs built housing for dislocated station workers. These are Bayulu and Wankajungka communities, respectively. Many Aboriginal people migrated to the town of Fitzroy Crossing, then found they were prevented from returning to their homelands. The 1970s was a time of great upheaval for most Kimberley Aborigines who found themselves spiritually divorced from their lands as well as materially disadvantaged in town camps and cramped housing developments like Bayulu. The period culminated in a movement for land rights legislation similar to the Northern Territory, but the West Australian legislative proposal failed in Parliament in 1984. In its place the Aboriginal Community Development Program brought a guarantee of Commonwealth funding for outstation infrastructure in tandem with a state government commitment to excise areas of pastoral stations for small Aboriginal 
homeland communities. This program changed the nature of the Fitzroy Valley. Eight communities have been established on Go Go station alone. These new settlements have developed new relationships with the water sources of the land, while also offering the opportunity for the preservation of traditional cultural values.

The presence of adequate water is a pre-condition for establishment of these small homeland communities. In a sense, Aboriginal people have once more found themselves in competition with pastoralists for water sources, since many excision applications have been rejected or modified because they required existing stock watering places such as bores. The original Yakanarra group first established themselves at Old Cherrabun station, where they had grown up but which is now abandoned. They moved to Mona Bore, Moankanambi, because the Cherrabun area is inundated in the wet season. They were persuaded to move back into Fitzroy Crossing by the Department of Community Development because their presence was thought to be interfering with stock, but then returned to the vicinity once more and set up camp some five or six kilometres from Mona Bore in 1989. Initially they carted water from the running bore to the camp. Later their own bore and a small water tank were installed. More recently a tank of much larger capacity filled by a solar powered pump has been erected. The provision of power, water and housing enables a well serviced community on the people's traditional land. There is also a non-government school. The community now numbers about 150 people. Contemporary relationships to the land and waters are necessarily different after a century of European occupation and modern living conditions for the Aboriginal community. Nevertheless, there is a strong relationship between the cultural practices and beliefs described in the first part of this chapter and the community's contemporary concerns.

The principal effect of abundant water supplies in bores and water holes is the possibility of over stocking the country with cattle, and subsequent environmental degradation. There are signs that this is a problem in this part of the Fitzroy catchment. Stock wander into the creek systems in search of water, destroying river banks which subsequently wash away in the wet season. Overpasturing leads to bare, dry, dusty plains. Lack of bore maintenance allows the waste of huge quantities of underground water annually. Some of the running bores in the vicinity of Yakanarra have been in operation since the earliest days of the stock enterprise. They have been placed in vicinity of jila. It seems very likely that the water that runs off and sinks into the surface does not replenish the underground source. While this is probably very large, it is not a completely inexhaustible resource and such a waste could easily be rectified. 


\section{Conclusion}

The people of Yakanarra continue to show their commitment to their ancestral lands through living on them and maintaining a highly viable community. It is clear from this description of cultural knowledge of water sources that they could also demonstrate the necessary criteria for recognition of their native title through occupancy and the maintenance of traditions. However, recognition of native title alone would not meet their current needs. The environmental degradation witnessed during this survey is linked in Walmajari thinking to the lack of proper cultural maintenance of water sources. There are fewer and fewer people who know the old rituals with each passing year. This is despite the fact that the young people are growing up understanding their own languages, familiar with the topography of their traditional environment, and at a suitable age participating in initiation ceremonies with other communities. Many cultural practices do survive, even if in a modified form. Nevertheless, there is a danger that some of the more local traditions and stories could disappear. Certainly, the relative scarcity of bush foods and fish, compared to the mature people's memories of their youth, is attributed to recent neglect of the kalpurtu. One author of this chapter (Boxer), along with other Walmajari people, has a vision of once more digging out the jila of Moankanambi, performing the correct secret ritual, singing the songs that make the kalpurtu happy, bringing rain and with it replenishing the earth. This would require bringing knowledgeable people from other communities, and would be an important experience for the youth of the community.

To the Walmajari way of thinking recognition of native title is without content if these activities cannot be performed. Yet recognition would not of itself provide the necessary resources and organisation to revitalise the rituals that Walmajari people believe are necessary to regenerate the land. One way of dealing with both Walmajari and mainstream priorities would be to develop a program of two-way environmental knowledge-sharing. It would be an opportunity to more clearly understand Aboriginal thinking on the nature of water and the regeneration of the land, and therefore the values that they would wish to see preserved in any proposals for water use. Secondly, it could lead to a program of conservation of water sources and monitoring of the use of the land that could produce the regeneration that the people so much desire. This program would involve members of Aboriginal communities themselves in active crosscultural pursuits that would produce useful results for both Aboriginal and non-Aboriginal users of the land. A necessary first step would be an audit of pastoral station water sources undertaken by community members with local knowledge. Conservation measures for rivers and other water sources would be identified. At the same time appropriate cultural activities and practices could be renewed with particular involvement of young adults. This would result 
in useful exchange of information between Aboriginal and non-Aboriginal culture with the potential for important practical outcomes. Commonwealth government initiatives such as declaration of an Indigenous Protected Area coupled with employment under the Working on Country could help preserve both the natural ecology and cultural knowledge. On its own, the recognition of native title rights cannot produce these outcomes. They require an alignment of priorities between settler and Aboriginal stakeholders, and a commensurate commitment of resources. This chapter will have achieved its purpose if it serves to lay the ground work for this important area of cross-cultural ecological management in the future.

\section{References}

Toussaint, S, P Sullivan, S Yu and M Mularty Jr 2001, ‘Fitzroy Valley Aboriginal cultural values study on water (a preliminary assessment)', unpublished report for the Water and Rivers Commission and the Centre for Anthropological Research, the University of Western Australia, Perth.

Vachon, D 2006, 'The Serpent, the Word and the Lie of the Land: the Discipline of Living in the Great Sandy Desert of Australia', unpublished PhD thesis, Graduate Department of Anthropology, University of Toronto, Toronto. 